\title{
A 1-YEAR PROSPECTIVE MONOCENTRIC STUDY OF LIMB, SPINAL AND PELVIC FRACTURES: CAN MONITORING FRACTURE EPIDEMIOLOGY IMPACT INJURY PREVENTION PROGRAMMES?
}

\author{
Václav Báča', Josef Klimeš², Václav Tolar², Petr Zimola², Ina Balliu², Ida Vitvarová2, Hana Lásková2, Valér Džupa ${ }^{3}$, \\ Michal Grivna ${ }^{4}$, Alexander Martin Čelko ${ }^{5}$ \\ ${ }^{1}$ Institute of Anatomy, Third Faculty of Medicine, Charles University, Prague, Czech Republic \\ ${ }^{2}$ Third Faculty of Medicine, Charles University, Prague, Czech Republic \\ ${ }^{3}$ Department of Orthopaedics and Traumatology, Third Faculty of Medicine, Charles University, and University Hospital Královské Vinohrady, \\ Prague, Czech Republic \\ ${ }^{4}$ Institute of Public Health, College of Medicine and Health Sciences, United Arab Emirates University, Al Ain, United Arab Emirates \\ 5 Institute of Epidemiology and Biostatistics, Third Faculty of Medicine, Charles University, Prague, Czech Republic
}

\begin{abstract}
SUMMARY
Objectives: The aim of this study was to assess fractures of extremities, spine and pelvis in patients with respect to mechanism, time of the incident and demography of patients in order to propose preventive measures.

Methods: A mono-centric (Level I Trauma Centre, predominantly urban population) prospective study was carried-out during the one-year period from 1 January to 31 December 2012. Patients with bone fractures of extremities, spine and pelvis were studied. Demography, mechanism and time of the injury were analysed.

Results: The study group consisted of 3,148 patients, $53 \%$ being women and treated for 3,909 fractures. The mean age of patients was 53 years. The most traumatised patients were of the 3rd and 4th decade, a further increase in the incidence of fractures was seen in the 7th and 9th decade. Multiple fractures were significantly higher in men $(p=0.002)$. A car crash or fall from a height was more common cause of spinal fracture or pelvic fracture than fracture to the upper or lower limbs $(p<0.001)$. Most of the fractures occurred during the day between 9 a.m. and 6 p.m., on Saturdays and during the winter season. The bones most often broken were the radius (739 patients, $18.5 \%$ ) and femur (436 patients, $11.1 \%$ ).

Conclusions: Our study highlights the need for injury prevention focused on sex, age and types of activities performed. Among younger individuals, such programmes should primarily be targeted toward men who, as observed in our sample, have a higher fracture frequency compared to women. Conversely, injury prevention programmes for individuals $\geq 60$ years should primarily be targeted toward women, who have the highest fracture prevalence in this population.
\end{abstract}

Key words: fractures of extremities, spinal fractures, pelvic fractures, injury prevention programmes

Address for correspondence: V. Džupa, Department of Orthopaedics and Traumatology, Third Faculty of Medicine, Charles University, and University Hospital Královské Vinohrady, Šrobárova 50, 10034 Prague, Czech Republic. E-mail: valer.dzupa@fnkv.cz

https://doi.org/10.21101/cejph.a5161

\section{INTRODUCTION}

Fractures, especially those occurring in osteoporotic bones, represent an enormous public health burden (1). They are relatively common with associated complicated treatments and high costs (2). In monitoring fractures and their causes, epidemiological and demographic data are important for the management of health care, for health insurance companies and for prevention. Epidemiological studies focused on the skeleton injury have different goals. For clinical management, it is important to know details of the precise anatomical location of fractures and their distribution in the population in order to plan and assess efficient treatment, to evaluate complications, and to monitor the time of hospitalisation (3-6). Studies based on the data from global and trans-regional databases are important for the organization of health care and the proposition of preventive measures $(1,7-12)$. Another important approach is to monitor injuries and their causes among certain population groups (13-18). The aim of this study was to describe external causes, seasonality and distribution of fractures of extremities, spine and pelvis in patients treated in Trauma Centre Level I.

\section{MATERIALS AND METHODS}

Data on skeletal fractures of extremities, spine and pelvis were collected prospectively at the Level I Trauma Centre from 1 January to 31 December 2012. The Trauma Centre is based at 
Faculty Hospital Královské Vinohrady in Prague. It is one of ten major centres in the Czech Republic covering a population of $1,250,000$ people ( $12 \%$ of the population of the Czech Republic) for specialized trauma care (polytraumas with Injury Severity Score $>16$ ). It serves also as a basic trauma care centre for part of the Prague population $(230,000)$. Fractures of the skull and ribs were excluded, because these fractures are part of the cranial and thoracic injuries, while we were only interested in limb and axial skeletal injuries. Variables on age and gender of the patient, anatomical location of fractures, external causes of fractures, and date and time of the injury were analysed. Data were extracted from patients' documentation and entered into a computer database (MS Excel) and then analysed using the Chi-square test of independence or the Fisher factorial test as appropriate. Probabilities of less than 0.05 were accepted as significant.

\section{RESULTS}

Out of total of 39,338 patients treated at the centre in 2012, $3,148(8 \%)$ patients with 3,909 fractures were included in the analysis, 1,668 (53\%) were women (Table 1); 1,521 (48.3\%) patients required hospitalization. The mean age of patients was 53 years (range 15-100 years, SD 22.5 years); for women the mean age was 62 years, for men 44 years (Fig. 1). The male patients in the 3rd and 4th decade accounted for almost half of all injured men (670 men, 46.6\%). In contrast, women were injured most often in the 7 th to 9 th decade (909 females, $54.5 \%$ ), while the proportion of men in these decades was only $21.8 \%$ (323 men).

\section{Number of Fractures}

By comparing patients with a single fracture and patients with multiple fractures, there was a significantly higher number of multiple fractures in men $(p=0.002)$ (Table 1).

\section{External Causes of Fractures}

A fall from the same level was the most frequent cause of fracture $(2,024,51.8 \%)$, followed by sport $(619,15.8 \%)$ (Table 2 ). Falls from the same level or fracture by a falling object were more often a cause of fractures of extremities than of the spine or pelvis $(p<0.001)$. A car crash or fall from a height were significantly more frequent in spinal or pelvic fractures than the upper or lower extremities $(\mathrm{p}<0.001)$. Car crashes and falls were the main causes of fractures in younger ages, especially in men (Table 3, Fig. 2). In older patients, especially among women, the major cause of fracture was fall from the same level (Table 3, Fig. 2). An assault resulted significantly more frequently in a fracture of the upper limb than the lower limb $(\mathrm{p}<0.001)$ or the spine $(p=0.006)$. Women injured in assaults were significantly older than men $(\mathrm{p}<0.001)$ (Table 3$)$.

Table 1. Distribution of single and multiple fractures by gender and age $(N=3,148)$

\begin{tabular}{|c|c|c|c|c|c|c|c|c|c|}
\hline & \multicolumn{6}{|c|}{ Gender } & \multicolumn{2}{|c|}{ Total } & \multirow{3}{*}{$\begin{array}{c}\text { Mean age } \\
\text { (years) }\end{array}$} \\
\hline & \multicolumn{2}{|c|}{ Female } & \multicolumn{2}{|c|}{ Male } & \multirow{2}{*}{$\begin{array}{c}\text { Female/Male } \\
\text { Ratio }\end{array}$} & \multirow{2}{*}{$p$} & \multirow{2}{*}{$\mathrm{n}$} & \multirow{2}{*}{$\%$} & \\
\hline & $\mathrm{n}$ & $\%$ & $n$ & $\%$ & & & & & \\
\hline Single fracture & 1,424 & 45.2 & 1,204 & 38.2 & $1: 0.85$ & 0.002 & 2,628 & 83.4 & 53 \\
\hline Multiple fractures & 244 & 7.8 & 276 & 8.8 & $1: 1.13$ & 0.002 & 520 & 16.6 & 55 \\
\hline Two & 175 & 5.6 & 174 & 5.5 & $1: 0.99$ & 0.283 & 349 & 11.1 & 57 \\
\hline Three & 33 & 1.0 & 41 & 1.4 & $1: 1.24$ & 0.178 & 74 & 2.4 & 50 \\
\hline Four & 13 & 0.4 & 15 & 0.5 & $1: 1.15$ & 0.610 & 28 & 0.9 & 51 \\
\hline Five and more & 23 & 0.8 & 46 & 1.4 & $1: 2$ & 0.001 & 69 & 2.2 & 49 \\
\hline Total & 1,668 & 53.0 & 1,480 & 47.0 & $1: 0.89$ & & 3,148 & 100 & 53 \\
\hline
\end{tabular}

Table 2. Distribution of fractures by external cause and anatomical region $(N=3,909)$

\begin{tabular}{|l|c|c|c|c|c|c|c|c|c|c|}
\hline \multirow{2}{*}{} & \multicolumn{2}{|c|}{ Upper extremities } & \multicolumn{2}{c|}{ Lower extremities } & \multicolumn{2}{|c|}{ Spine } & \multicolumn{3}{c|}{ Pelvis } & \multicolumn{2}{c|}{ Total } \\
\cline { 2 - 13 } & $\mathbf{n}$ & $\%$ & $\mathbf{n}$ & $\%$ & $\mathbf{n}$ & $\%$ & $\mathrm{n}$ & $\%$ & $\mathrm{n}$ & $\%$ \\
\hline Car crash & 42 & 27.5 & 54 & 35.3 & 35 & 22.9 & 22 & 14.4 & 153 & 3.9 \\
\hline Motorbike & 28 & 40.0 & 28 & 40.0 & 8 & 11.4 & 6 & 8.6 & 70 & 1.8 \\
\hline Pedestrian & 39 & 27.7 & 62 & 44.0 & 26 & 18.4 & 14 & 9.9 & 141 & 3.6 \\
\hline Fall from the same level & 965 & 47.7 & 852 & 42.1 & 132 & 6.5 & 75 & 3.7 & 2,024 & 51.8 \\
\hline Fall from height & 96 & 27.2 & 103 & 29.2 & 98 & 27.8 & 56 & 15.9 & 353 & 9.0 \\
\hline Sport & 385 & 62.2 & 185 & 29.9 & 29 & 4.7 & 20 & 3.2 & 619 & 15.8 \\
\hline Falling object & 207 & 49.8 & 192 & 46.2 & 11 & 2.6 & 6 & 1.4 & 416 & 10.6 \\
\hline Assault & 67 & 67.7 & 21 & 21.2 & 6 & 6.1 & 5 & 5.1 & 99 & 2.5 \\
\hline Suicide & 10 & 29.4 & 7 & 20.6 & 11 & 32.4 & 6 & 17.6 & 34 & 0.9 \\
\hline Total & 1,839 & 47.0 & 1,504 & 38.5 & 356 & 9.1 & 210 & 5.4 & 3,909 & 100 \\
\hline
\end{tabular}


Table 3. Distribution of fractures by external cause and gender $(N=3,148)$

\begin{tabular}{|c|c|c|c|c|c|c|c|c|c|c|c|}
\hline & \multicolumn{8}{|c|}{ Gender } & \multicolumn{3}{|c|}{ Total } \\
\hline & \multicolumn{3}{|c|}{ Female } & \multicolumn{3}{|c|}{ Male } & \multirow{2}{*}{$\begin{array}{c}\text { Female/Male } \\
\text { Ratio }\end{array}$} & \multirow[b]{2}{*}{$p$} & \multirow[b]{2}{*}{$\mathrm{n}$} & \multirow[b]{2}{*}{$\%$} & \multirow[b]{2}{*}{$\begin{array}{c}\text { Mean age } \\
\text { (years) }\end{array}$} \\
\hline & $\mathrm{n}$ & $\%$ & $\begin{array}{c}\text { Mean } \\
\text { age }\end{array}$ & $\mathrm{n}$ & $\%$ & $\begin{array}{l}\text { Mean } \\
\text { age }\end{array}$ & & & & & \\
\hline Car crash & 29 & 0.9 & 41 & 60 & 1.9 & 42 & $1: 2.1$ & $<0.001$ & 89 & 2.8 & 42 \\
\hline Motorbike & 3 & 0.1 & 24 & 34 & 1.1 & 37 & $1: 11.3$ & $<0.001$ & 37 & 1.2 & 36 \\
\hline Pedestrian & 41 & 1.3 & 58 & 40 & 1.3 & 53 & $1: 0.9$ & 0.751 & 81 & 2.6 & 55 \\
\hline Fall from the same level & 1,248 & 39.6 & 68 & 551 & 17.5 & 55 & $1: 0.4$ & $<0.001$ & 1,799 & 57.1 & 64 \\
\hline Fall from height & 40 & 1.3 & 50 & 156 & 5.0 & 45 & $1: 3.9$ & $<0.001$ & 196 & 6.3 & 46 \\
\hline Sport & 154 & 4.9 & 37 & 369 & 11.7 & 33 & $1: 2.4$ & $<0.001$ & 523 & 16.6 & 34 \\
\hline Falling object & 131 & 4.2 & 42 & 216 & 6.9 & 37 & $1: 1.7$ & $<0.001$ & 347 & 11.1 & 39 \\
\hline Assault & 17 & 0.5 & 48 & 51 & 1.6 & 32 & $1: 3$ & $<0.001$ & 68 & 2.1 & 36 \\
\hline Suicide & 5 & 0.2 & 46 & 3 & 0.1 & 36 & $1: 0.6$ & NS & 8 & 0.3 & 42 \\
\hline Total & 1,668 & 53.0 & 62 & 1,480 & 47.0 & 44 & $1: 0.9$ & & 3,148 & 100 & 53 \\
\hline
\end{tabular}

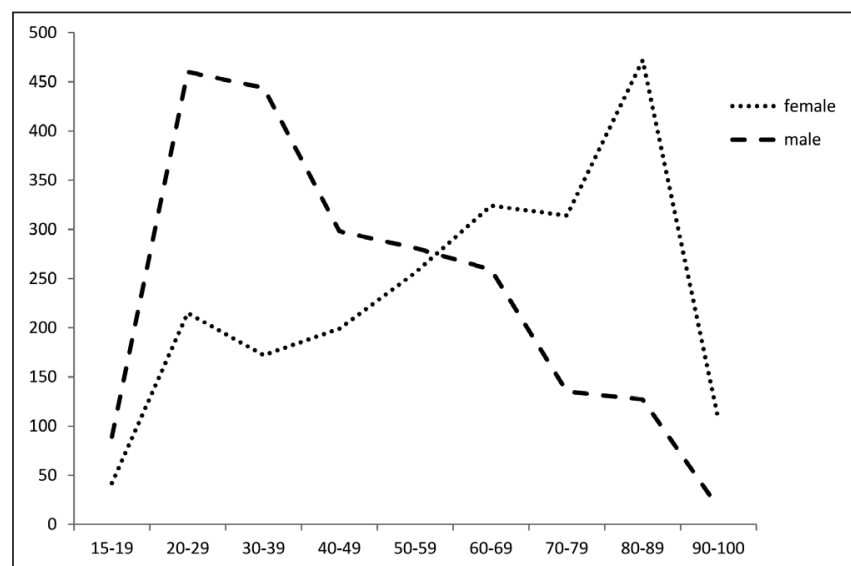

Fig. 1. Distribution of patients with fractures by age group and gender.

\section{Time of Fracture Occurrence}

During the week, the highest incidence was on Saturday (Fig. 3a); this distribution was evidenced primarily in male fractures. Most of the fractures occurred during the day between 9 a.m. and 6 p.m. (Fig. 3b). For men, the peak incidence of fractures was between 6 p.m. and 9 p.m. During the year, the highest number of fractures was observed in the winter (Fig. 3c).

\section{Anatomical Site of Fractures}

Of the 3,909 evaluated fractures, the most frequently broken bones were the radius (739 patients, 18.5\%) and femur (436 patients, $11.1 \%$ ) (Table 4). When comparing the gender distribution, women had a significant predominance in fractures of proximal humerus $(p<0.001)$, distal radius $(p<0.001)$ and proximal femur $(p<0.001)$. Men were significantly predominant in fractures of the clavicle $(p<0.001)$, bones of carpus $(p<0.001)$, metacarpus $(p<0.001)$, and finger phalanges $(p<0.001)$, then calcaneus $(\mathrm{p}<0.001)$, metatarsus $(\mathrm{p}<0.001)$ and lumbar vertebrae $(\mathrm{p}=0.007)($ Table 4$)$.

\section{Age and Anatomical Region of Fractures}

The distribution of fractures in anatomical regions by age are shown in Figure 4. In order to illustrate better the relation between various bone fractures and age, fractures that have a statistically significant difference between women and men are shown in Figure 5. Fractures occurring mainly in women (proximal humerus, distal radius, proximal femur) are illustrated with individual curves, while other fractures of the upper and lower limbs, which occurred more in men, are grouped into two curves. It is clear that fractures in women occurred predominantly in older age groups, while fractures in men occurred mostly in young patients. With increasing age, frequency decreased (Fig. 5).

\section{DISCUSSION}

Fractures were more common in younger men and in women aged over 60 . Women had significantly more fractures considered to be osteoporotic (proximal humerus, distal radius, proximal femur). Men were more often injured in traffic crashes, in falls from height and while doing sports. Women were more often injured in fall from the same level.

The age distribution of patients with fractures showing two peaks in the 3rd and 4th decade and in the 7th to 9th decade was reported in other studies $(9,11)$. The larger proportion of men in the younger age groups is possibly related to hazardous work and sport $(5,13,14)$. It has been described previously that the increased incidence of osteoporotic fractures (proximal humerus, distal radius, proximal femur) in elderly women is caused by postmenopausal osteoporosis $(3,4,7,12,19,20)$. Another important factor is related to longer mean survival time among women (3, $12,19)$. Both of these findings are consistent with the results of an earlier study (21).

The predominance of multiple fractures in men relates to their riskier behaviour in the context of work and sport activities. This has been indicated also by other studies $(9,13,14)$. Interestingly, a decline in the number of fractures in men in the 5th and 6th decade was not very steep. A previous epidemiological study of 


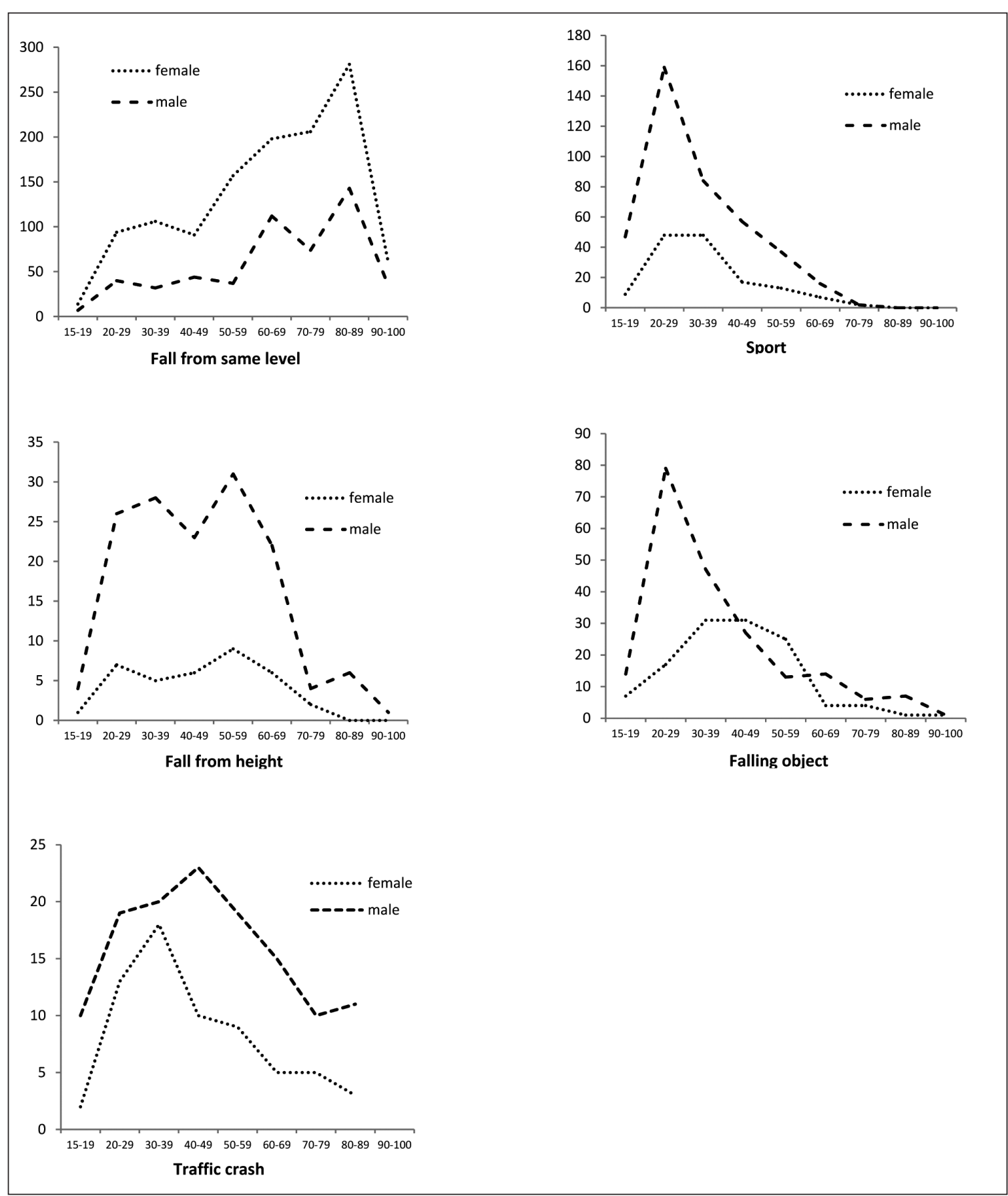

Fig. 2. External cause of fractures by age group and gender.

the incidence of musculoskeletal injuries proved that fractures of extremities, spine and pelvis account for about a quarter of all fractures, and that the most injured area is the wrist and hand (21). The finding that fractures occur more often in men of younger age groups is consistent with other studies $(11,16)$. Spinal and pelvic fractures were possibly caused by high impact injuries. Skeletal limb fractures occur predominantly in same-level falls and injuries from falling objects, findings similar to other studies $(11,20,22)$.

A fall from the same level was the most predominant cause of fractures in this study, especially among women. It has caused almost three quarter of all fractures. Especially among the elderly, falls can cause serious injury and death $(9,23,24)$. Every year $30 \%$ to $60 \%$ of the elderly fall and half of them have multiple falls (25, 26). In a U.S. study, injury severity and mortality for same-level falls was twice that of young people (23). In 2012, 90\% of women who died as result of a fall in the Czech Republic were over 65 years of age in comparison to only $64 \%$ of men (27). The higher proportion of fractures in men from falls from height in this study is possibly influenced by work-related activities. Male preponderance in fractures in traffic crashes was not surprising. Traffic injuries can be effectively influenced by enforced legislation, while sport fractures may be effectively prevented by awareness and the use of appropriate equipment. Prevention of falls, especially in the elderly, requires a complex approach focusing on physical, cognitive, behavioural and environmental areas, particularly in relation to the increasing prevalence of osteoporosis.

The finding of a significantly higher number of bone fractures of the upper extremities than lower extremities or spine during an 


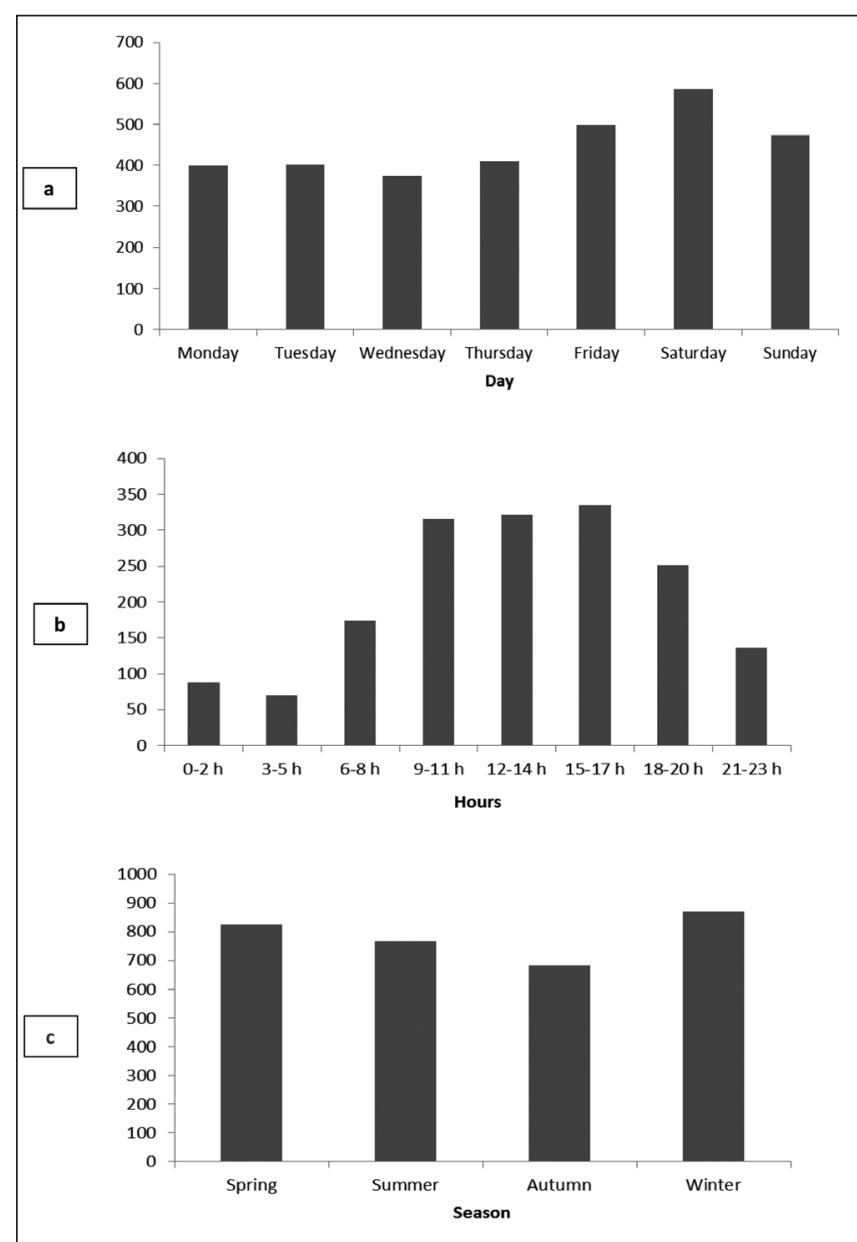

Fig. 3. Distribution of patients with fractures by day of the week (a), hour of the day (b) and season of the year (c).

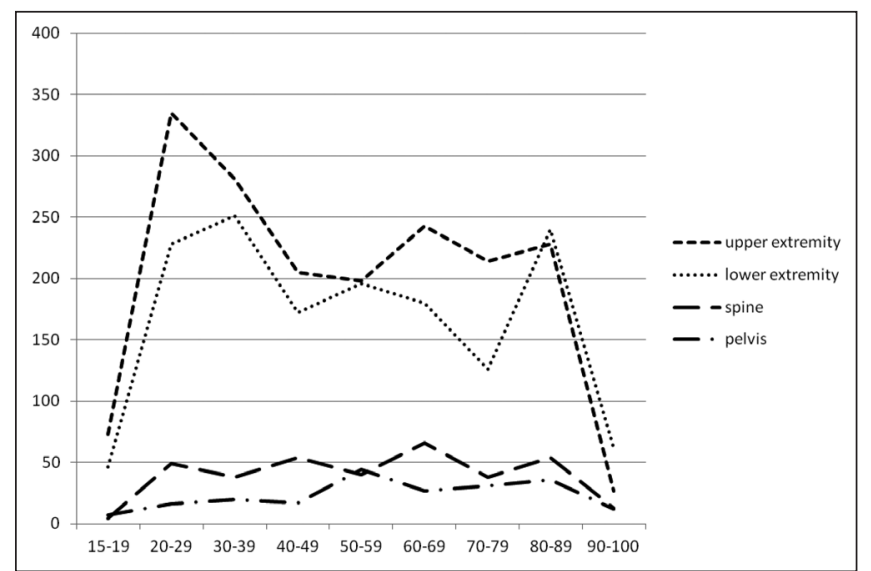

Fig. 4. Age distribution of fractures by locations and decades.

assault is noteworthy. This is probably related to the protection of the head and face during assault by the victim pushing out the upper extremities, and also to the efforts to temper the effects of the fall with upper extremities while falling to the ground (11).

The highest incidence of fractures in men between 6 p.m. and 9 p.m. and on weekends with a peak on Saturdays indicates connection with sport activities during leisure time. No similar statements were found in other studies.

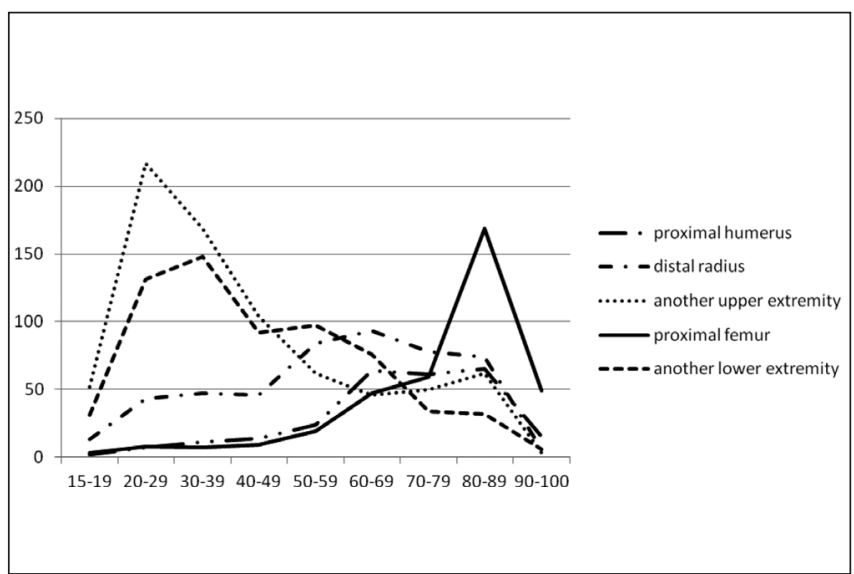

Fig. 5. Age distribution of the most common fractures (more than 100 for the monitored period of one year) by decades.

\section{Limitations of Our Study}

Patients with fractures of the skull and ribs were not included in the study. These fractures are a part of cranial and thoracic injuries. This study is concerned only with skeletal fractures of the musculoskeletal system, which are considered a separate issue. The lowest age of patients was 15 years, as the Trauma Centre treats only adult patients. The centre is located in a large urban cluster, which can affect the spectrum of fractures. Two other Trauma Centres Level 1 operate in the city and patients seek treatment either by themselves or are brought by ambulance to the nearest Trauma Centre from the site of injury. For this reason, it is difficult to have a proper denominator for the calculation of incidence rates of individual fractures. Another reason is that many patients with less severe fractures seek treatment in other medical facilities operating in the region. The comparison of our results with other studies is challenging because the design and data collection of epidemiological studies vary, and they are often influenced by regional factors like the provision of health care, classification schemes, structure of the population, risk factors, culture etc. $(2-4,9,10)$.

\section{CONCLUSION}

Our study highlights the need for injury prevention programmes focused on sex, age, and types of activities performed.

Among younger individuals, such programmes should primarily be targeted toward men who, as observed in our sample, have a higher fracture frequency compared to women. These preventive programmes should focus on male risk-taking behaviours (motorsports and cycling, in particular) and work-related activities with potential exposure to high energy (e.g., heavy loads and machinery, working at great heights, etc.), which is the cause of the significantly greater number of multiple fractures, and serious spinal or pelvic injuries seen in men. The increased incidence of fractures sustained by men during weekends, especially Saturdays, underscores the need to focus these programmes also on male leisure activities (e.g., sports and do-it-yourself projects).

Conversely, injury prevention programmes for individuals $\geq 60$ years should primarily be targeted toward women, who have the highest fracture frequency in this population. The increased 
Table 4. Distribution of fractures by anatomical site and gender $(N=3,909)$

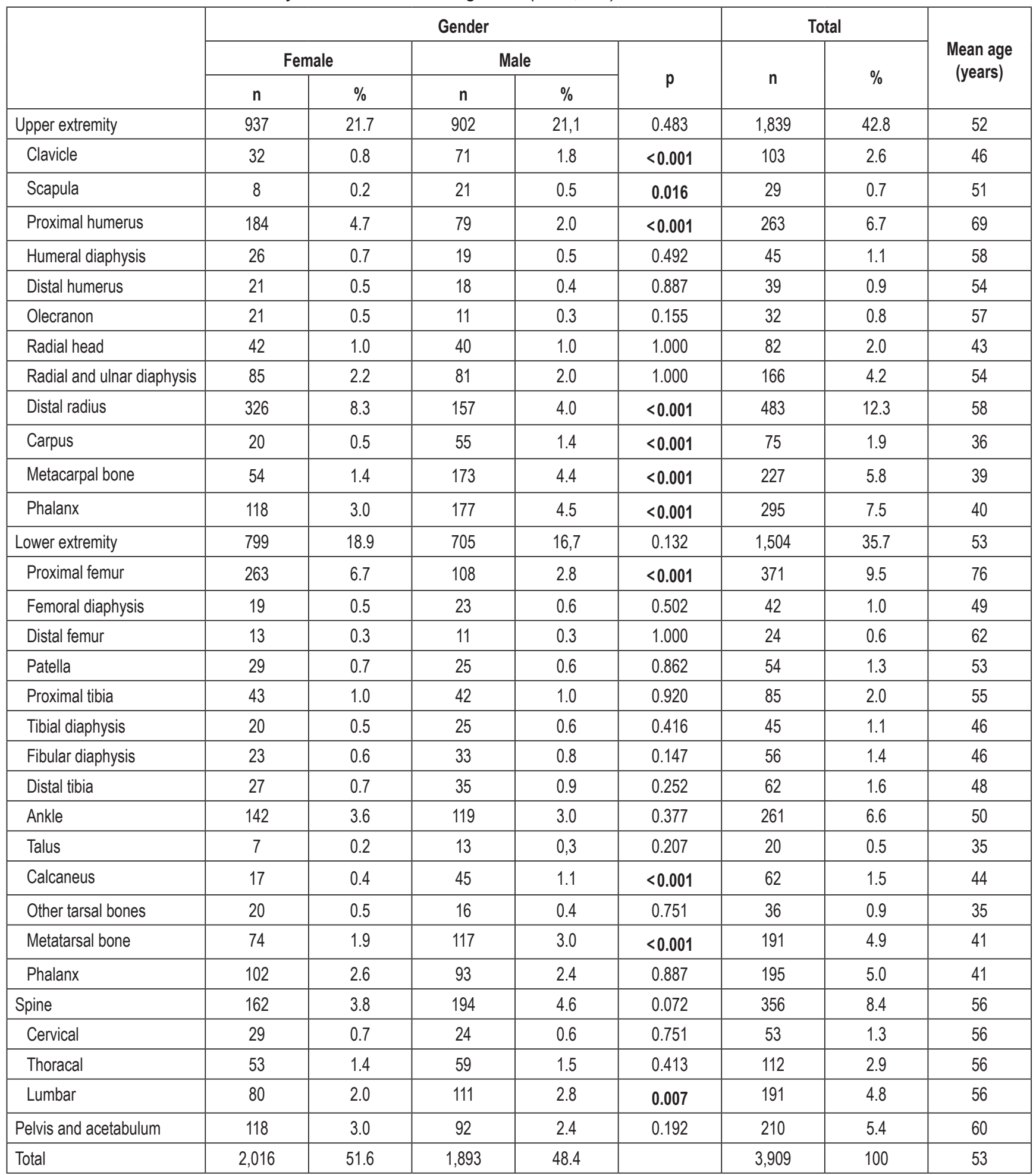

frequency is due to the predominance of osteoporotic limb fractures among women over 60 years (e.g., proximal humerus, distal radius, proximal femur). Such fractures can occur after a simple fall; therefore, these programmes should encompass a complete set of measures to reduce the risk of falling not only outdoors but, equally important, within the home. Another important public health issue, which is currently advocated, is a lifelong prevention of osteoporosis, which can reduce the risk of an osteoporotic limb and spinal fractures.

\section{Acknowledgements}

The study was supported by research grants of the Charles University, Prague, Czech Republic No. SVV 266701/2013 and SVV 260385/2016 The authors are grateful to Alena Vokounová and Svetlana Bilenka for their help with patient data collection. Mr John Anthony Barrett M. Phil, English lecturer, helped with revision of the final draft.

\section{Conflict of Interests}

None declared 


\section{REFERENCES}

1. van Staa TP, Dennieson EM, Leufkens HGM, Cooper C. Epidemiology of fractures in England and Wales. Bone. 2001;29(6):517-22.

2. Court-Brown CM, Caesar B. Epidemiology of adult fractures: a review. Injury. 2006;37(8):691-7.

3. Balk R, Hahn F, Tarcea B. Proximal femur fracture. Frequency. Demography. Etiology. Prophylaxis. OP-Journal. 2002;18(2):80-4. (In German.)

4. Cuenca J, Martinez AA, Herrera A, Domingo J. The incidence of distal forearm fractures in Zaragoza (Spain). Chir Main. 2003;22(4):211-5.

5. Madadi F, Vahid Farahmandi M, Eajazi A, Daftari Besheli L, Madadi F, Nasri Lari M. Epidemiology of adult tibial schaft fractures: a 7-year study in a major referral orthopedic center in Iran. Med Sci Monit. 2010;16(5):CR217-21.

6. Pscherer S, Sandmann GH, Ehnert S, Nussler AK, Stöckle U, Freude T. Delayed fracture healing in diabetics with distal radius fractures. Acta Chir Orthop Traumatol Cech. 2017;84(1):24-9.

7. Black DM, Cooper C. Epidemiology of fractures and assessment of fracture risk. Clin Lab Med. 2000;20(3):439-53.

8. Curtis JR, Taylor AJ, Matthews RS, Ray MN, Mecker DJ, Gary LC, et al. „Pathologic“ fractures should these be included in epidemiologic studie of osteoporotic fractures? Osteoporos Int. 2009;20(11):1969-72.

9. Klop C, van Staa TP, Cooper C, Harvey NC, de Vries F. The epidemiology of mortality after fracture in England: Variation by age, sex, time, geographic location, and ethnicity. Osteoporos Int. 2017;28(1):161-8.

10. Melton LJ 3rd, Crowson CS, O'Fallon WM. Fracture incidence in Olmsted County, Minnesota: Comparison of urban with rural rates changes in urban rates over time. Osteoporos Int. 1999;9(1):29-37.

11. Osmaya-Moreno H, Romero-Espinosa JF, Mondragon-Chimal MA, Ochoa-Gonzales G, Escoto-Gomez JA. Epidemiological study of traumatic hand injuries in Toluca, State of Mexico. Cir Cir. 2014;82(5):511-6. (In Spanish.)

12. Zebaze RMD, Seeman E. Epidemiology of hip and wrist fractures in Cameroon, Africa. Osteoporos Int. 2003;14(4):301-5.

13. Badekas T. Foot and ankle injuries during the Athens 2004 Olympic Games. Med Chir Pied. 2010;26:9-12.

14. Cho CH, Song KS, Min BW, Lee SM, Chang HW, Eum DS. Musculoskeletal injuries in break-dancers. Injury. 2009;40(11):1207-11.

15. Fields KB. Running injuries: changing trends and depografics. Curr Sports Med Rep. 2011;10(5):299-303.
16. Gupta A, Gupta AK, Uppal SK, Mittal RH, Garg R, Aggarwal N. Demographic profile of hand injuries in an industrial town of North India: a review of 426 patients. Ind J Surg. 2013;75(6):454-61.

17. Jonsson BY, Siggeirsdottir K, Mogensen B, Sigvaldason H, Sigurdsson G. Fracture rate in a population-based sample of men in Reykjavik. Acta Orthop Scand. 2004;75(2):195-200.

18. Swenson DM, Yard EE, Collins CL, Fields SK, Comstock RD. Epidemiology of US high school sports-related fractures, 2005-2009. Clin J Sport Med. 2010;20(4):293-9.

19. Hamplova L, Mazalanova A, Nemcova J, Moravcova K, Jextova S. Injuries to the elderly in the Czech Republic. Monit Med SLS. 2014;12:25-6. (In Czech.)

20. Giannini S, Sella S, Rossini M, Braghin D, Gatti D, Vilei MT, et al. Declinning trends in the incidence of hip fractures in people aged 65 years over in years 200-2011. Eur J Intern Med. 2016;35:60-5.

21. Skapinec P, Tislicky J, Dzupa V, Prochazka B. Trauma diagnosed in patients treated at the traumatological out-patient clinic throughout the winter months. Osteol Bull. 2005;10(2-3):27-32. (In Czech.)

22. Grivna M, Eid HO, Abu-Zidan FM. Injuries from falling objects in the United Arab Emirates. Int J Inj Contr Saf Promot. 2015;22(1):68-74.

23. Sterling DA, O'Connor JA, Bonadies J. Geriatric falls: injury severity is high and disproportionate to mechanism. J Trauma. 2001;50(1):116-9.

24. Woo J, Leung J, Wong S, Kwok T, Lee J, Lynn H. Development of a simpla scoring tool in the primary care setting for prediction of recurrent fals in men and women aged 65 years and over living in the community. J Clin Nurs. 2009;18(7):1038-48.

25. Ayoung-Chee P, McIntyre L, Ebel BE, Mack CD, McCormick W, Maier RV. Long-term outcomes of ground-level falls in the elderly. J Trauma Acute Care Surg. 2014;76(2):498-503.

26. McClure R, Turner C, Peel N, Spinks A, Eakin E, Hughes K. Population-based interventions for the prevention of fall-related injuries in older people. Cochrane Database Syst Rev. 2005;25(1):CD004441. doi: 10.1002/14651858.CD004441.pub2.

27. IHIS CR. Deaths 2012. Prague: IHIS CR; 2013. (In Czech.)

Received June 23, 2017

Accepted in revised form October 30, 2018 